\title{
Modeling and improvement of the tricycle braking system for controlled skidding
}

\author{
Robert-Marian Bleotu ${ }^{1, *}$, and Cosmin Preda ${ }^{1}$ \\ 1'Lucian Blaga" University of Sibiu, Faculty of Engineering, Str. Emil Cioran Nr. 4, 550025, \\ Romania
}

\begin{abstract}
In the current paper was approached the braking system of tricycles for controlled skidding, which are used by lovers of extreme sports. The complete modeling of such a tricycle has been performed and its braking system has been improved for a great performance and a better controlled braking. Also, simulation tests were performed using the finite element to achieve the best constructive variant of the brake disc.
\end{abstract}

\section{Introduction}

\subsection{Bike trike for controlled skidding}

For the model studied was used a combination between a kart and a bike. It is used by adrenaline enthusiasts for different high speed sports.

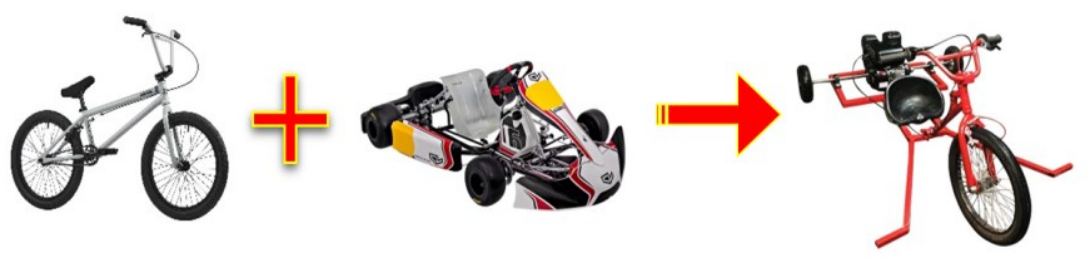

Fig. 1. Combination between BMX bike and a motorized kart.

The inventors of special made tricycle destined for controlled skidding took over from the bicycles the front part made up of the wheel, fork and guide assembly, and from the karts they took over its rear part, more precisely the motorized part [1] [2]. The brakes are very demanding, they are used almost permanently by the user. Drifting tricycles are equipped with different braking mechanisms, both on the back and on the front of it [3]. Many of low budget tricycles are made by home users, as they are easy vehicles to make.

With the help of the Creo 3.0 program, the 3D mode of such a tricycle model for controlled skidding was created. As can be seen, the current model is made of the following groups of components shown in Table 1 and then presented in Fig. 2.

\footnotetext{
${ }^{*}$ Corresponding author: robert.bleotu@ulbsibiu.ro
} 
Table 1. Component items of tricycle.

\begin{tabular}{|c|c|}
\hline Nr. & Part name \\
\hline 1. & Engine \\
\hline 2. & Metal frame \\
\hline 3. & Rear axle \\
\hline 4. & Kart wheels \\
\hline 5. & Braking system \\
\hline 6. & BMX wheel \\
\hline
\end{tabular}

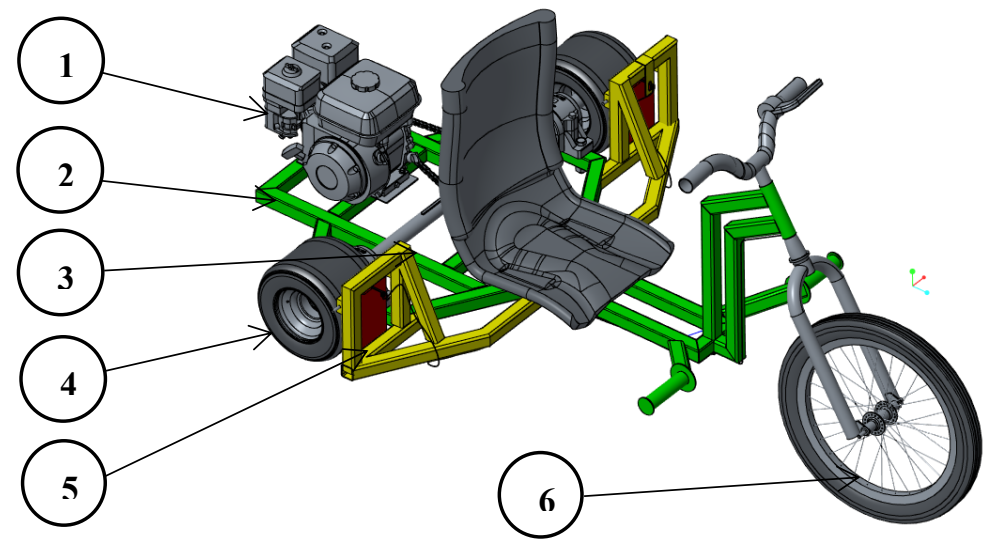

Fig. 2. Component elements of the tricycle.

\subsection{Braking system}

Initial braking system is a simple one made of a support on each side of the wheel, two dampers that rotate around an axis and the mechanically operated cap. In this case, the working principle of this system: the user presses the brake lever with his left hand, at this moment the mechanical cable actuates the damper, this performing the braking through the forced contact between it and the wheel.
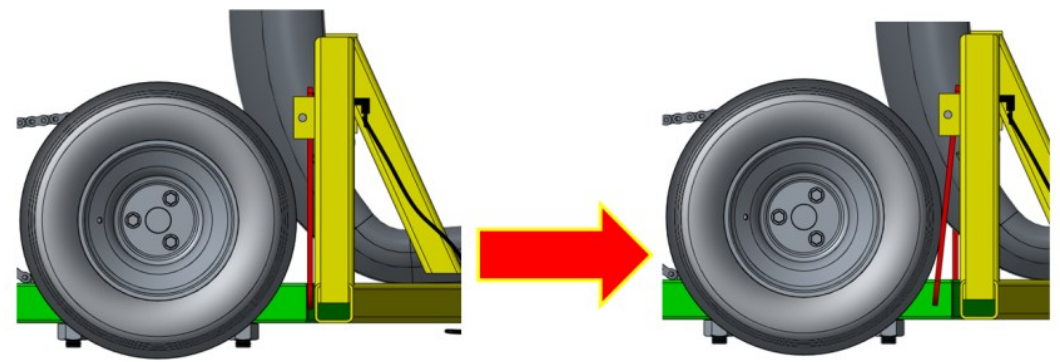

Fig. 3. Braking system not activated and activated. 


\section{Objectives}

The main objective of this paper is to highlight the differences between three types of braking systems, used for the construction of the tricycle, those models were created with the help of the CREO 3.0 program [4, 5]. It also aims to improve the brake discs in terms of the temperature at which it is exposed [6]. Five different types of brake discs will be analyzed in terms of their geometry, for their analysis the same type of material will be used, a semi-metallic material. Following the first set of data, the best result will be extracted, and a new set of analyzes will be performed on this disc, this time on the type of material. The program in which all the analysis sets will be performed is the ANSYS finite element simulation program.

\section{Manufacturing technology and sustainable development}

Numerous studies have been conducted regarding the study and optimization of the vehicle braking system. In the context of creating a new tricycle model and improving the braking system, the following areas were analyzed:

a) Thermal analysis on discs has a very important role in this paper because it studies the ability of discs to overheat when they are overloaded [7].

b) Modeling and analysis of new disc concepts. Different models of discs have been made to facilitate their efficiency: discs without ventilation, discs with external ventilation or discs with internal ventilation [8].

c) Design of new tricycle prototypes. The aim is to improve the comfort and exterior design of tricycles like this by replacing the profiles used in their construction, the seat, the braking system or the motorization for tricycles intended for controlled skidding [9].

\section{Modeling of three types of tricycles for controlled skidding}

\subsection{Variant I - Braking system specific to road vehicles}

For the first constructive variant we tried to use the braking system from classic cars, but at a much lower level in terms of its complexity. Thus, for the first constructive variant of improvement, a braking system was chosen consisting of the brake disc - brake pad assembly, the discs being placed on each of the two rear wheels.

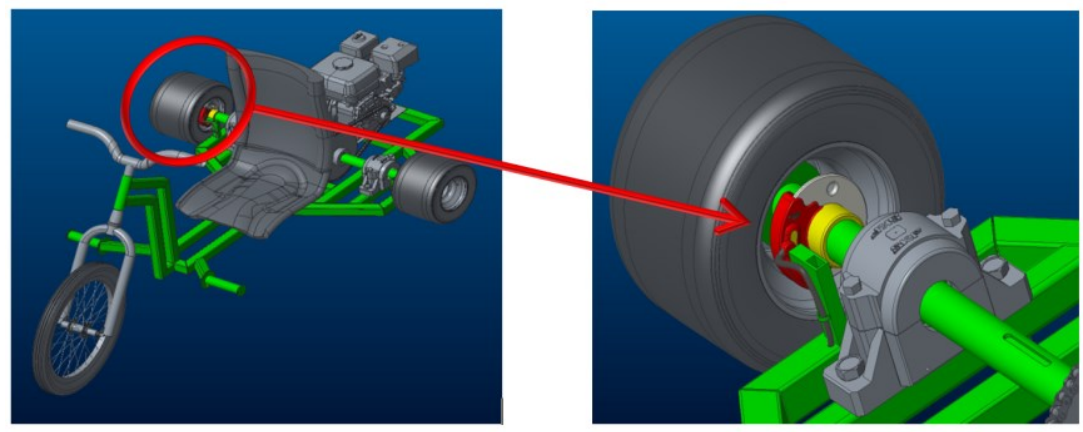

Fig. 4. Braking system specific to road vehicles. 
The aim was to significantly increase the braking quality, a lower temperature, resulting from the process. From a mechanical point of view, there will be an increase in the complexity of the braking system, because, compared to the braking variant with the brake pad on the wheel, there will be brake pads that act on the discs. Removing the brake pad supports from the previous version thus eliminates a significant weight of material, which would lead to improved performance and an aerodynamic shape.

The principle of operation of the braking system is based on the transmission of the driving force, exerted by the driver on the lever, the wire cable starts from the relaxed position and reaches a state of traction. Thus, it forces the brake pads positioned in the caliper to press on both sides on the brake disc, in the end the wheel being forced to stop.

\subsection{Variant II - Braking system specific to bicycles}

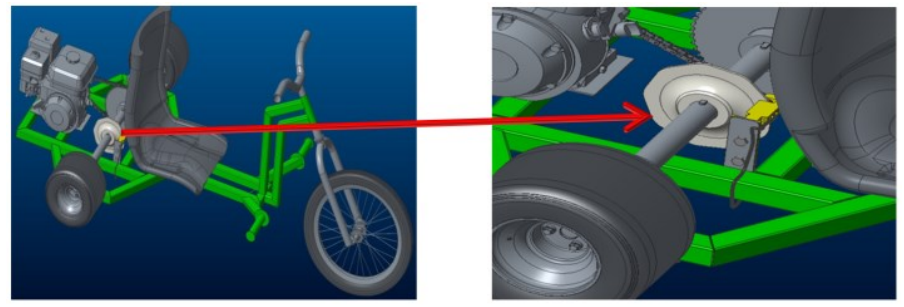

Fig. 5. Braking system specific to bicycles.

The braking variant used here is the most common in this field, being often preferred for karts used in amateur racing. Due to the fact that it has only one braking mechanism fixed on the rear axle, the braking forces are evenly distributed on the two wheels. As can be seen, this time only one disc was used to brake the tricycle. The brake disc is positioned on the axis of the tricycle, its torque being ensured by the parallel wedge assembly. Its fixing is done with the help of a flange welded on the central axis.

\subsection{Variant III - Hydraulic braking system, with individual actuation of each wheel}

This last constructive variant, which has as main purpose, the improvement of the braking systems for the tricycles destined for the controlled skidding, brings the combination between the first two constructive variants.

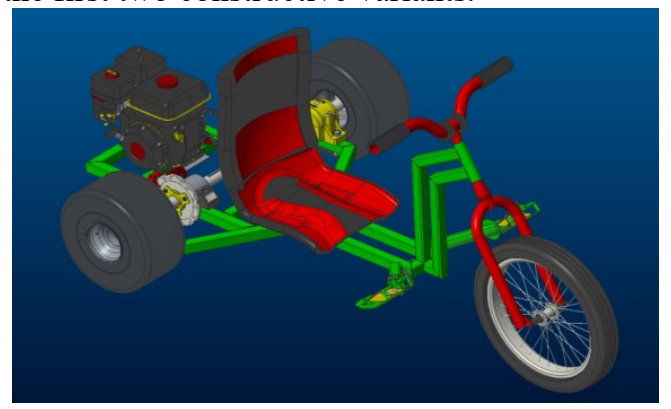

Fig. 6. Hydraulic braking system, with individual actuation of each wheel.

The new braking system is a hydraulic type, which replaces the classic mechanical wire system with the fluid that is put under pressure in the pipes. This improvement has been made due to the multiple benefits of the hydraulic system compared to the mechanical one. 
It was concluded that replacing the lever with a brake pedal is much more beneficial in terms of agility and reaction speed. The brake pedals are located in the foot support areas, one on each side. The main advantage that defines this new type of braking is the fact that the brake is made on each wheel separately and it has two different brake discs for each side.

Principle of operation: The driver actuates the left pedal when he wants to lock the leftrear wheel, the tricycle skids to the right. When the driver wants to lock the right-rear wheel, the right pedal will operate, the skid is done to the left.

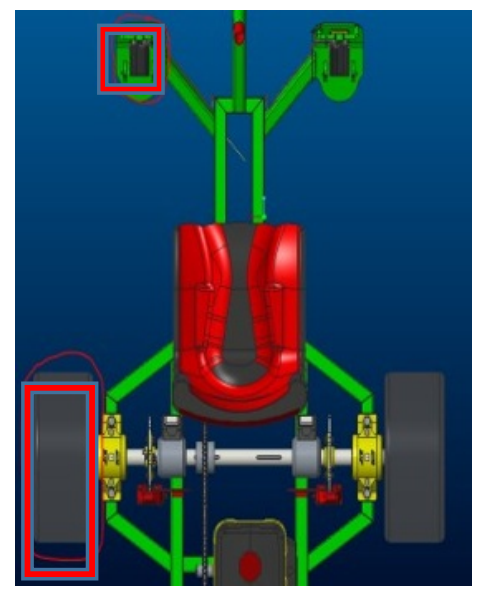

Fig. 7. Left wheel lock.

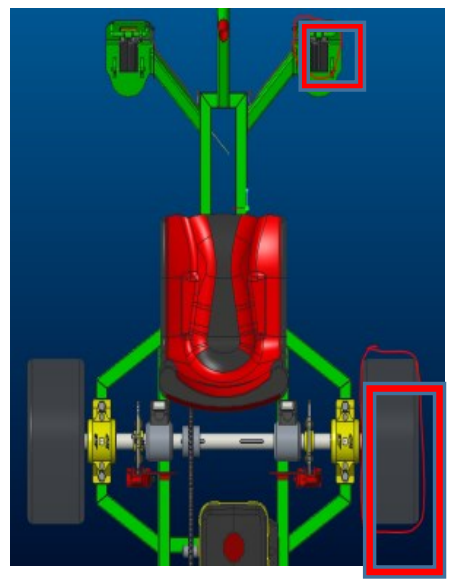

Fig. 8. Right wheel lock.

Following the research and modeling of the three constructive variants of the braking system, it was concluded that the third constructive variant is the most able to achieve a more efficient braking in terms of temperature values obtained. One of the most important elements of this braking system as a whole is the brake disc.

It has an important role in the quality of a good braking, because the disc is very demanding during the use of the tricycle. The disk reaches high temperatures, so we will continue to study different types of disk geometry, as well as the material from which they are made. The type of analysis used to identify the best solution is thermal analysis.

\section{Modeling of five types of discs for braking system}

The modeling program in which the five constructive disc variants were made was the CATIA V5 program. Then, models were imported into ANSYS simulation software for finite element simulation analysis.

The brake discs models for thermal analysis are presented below in table 1, including their mesh network, was used a triangular surface mesh [10]. The number of nodes and elements for all five models are different, varying from 11834 elements for disc variant 1 to 74903 elements for disc variant 4 , which has a more complex design.

A Steady State Thermal analyzes were performed for each individual brake disc, considering a braking period of 10 seconds, and an ambient temperature of $22^{\circ} \mathrm{C}$. 
Table 2. Results obtained.

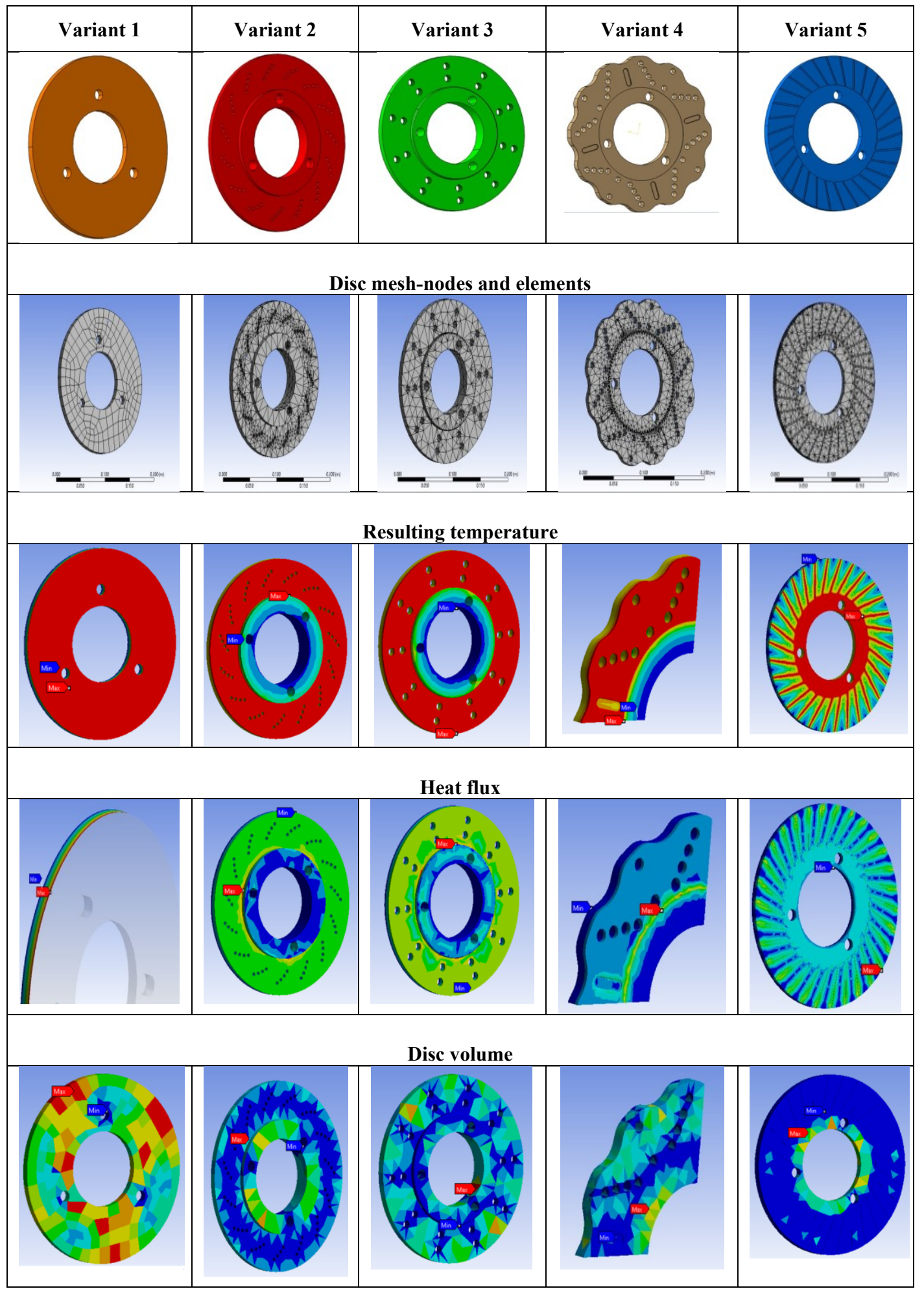




\subsection{Brake disc geometry}

\subsubsection{Disc variant 1 - results obtained}

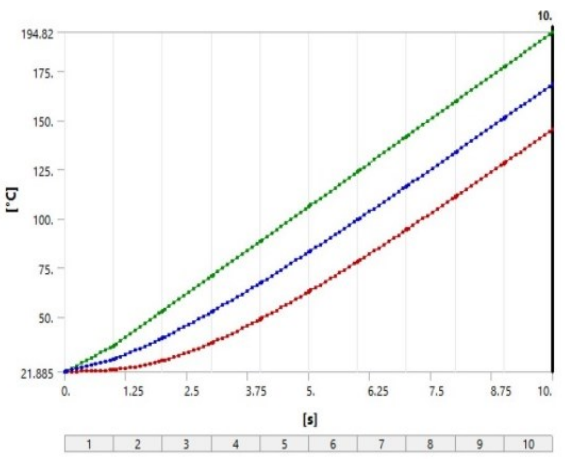

Fig. 9. Time-temperature graph: disc 1.

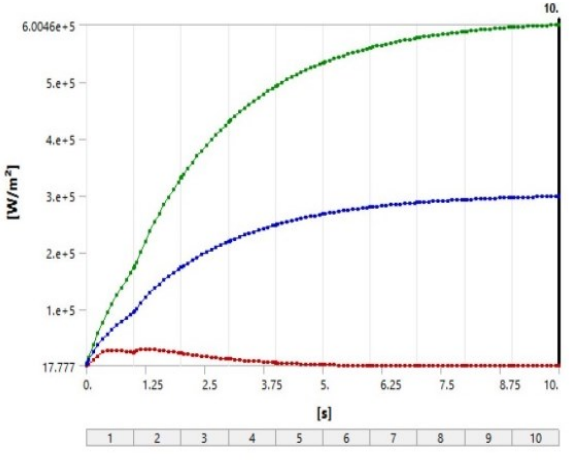

Fig. 10. Heat flow-time graph: disc 1.

In this first disc variant a simple geometry was used, the material used being semimetal, and the disc thickness is $10 \mathrm{~mm}$. As can be seen from the analysis performed on this disc variant, the maximum temperature reached by the disc in an interval of 10 seconds is $194.82^{\circ} \mathrm{C}$, as can be seen in Fig. 9. Regarding the heat flux, a maximum value of $6.0046 \mathrm{e}+5 \mathrm{~W} / \mathrm{m}^{2}$ can be observed in Fig. 10. You can also see the distribution of heat flux on the first disk variant in Table 2.

\subsubsection{Disc variant 2 of the disc - results obtained}

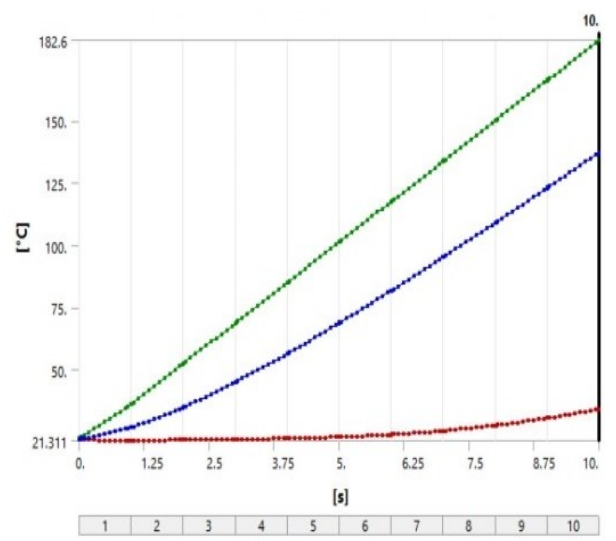

Fig. 11. Time-temperature graph: disc 2 .

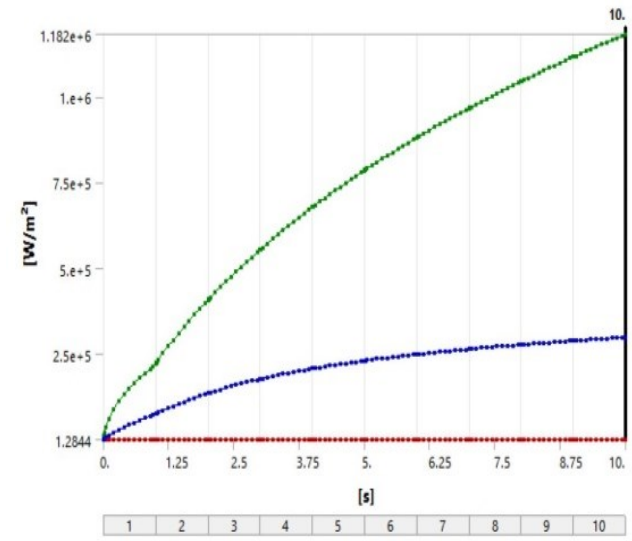

Fig. 12. Heat flow-time graph: disc 2.

In this second disc variant, a geometry was used that contains small diameter disc ventilation perforations, which follow a certain curve, the material used being semi-metal, and the disc thickness is $10 \mathrm{~mm}$. As can be seen from the analysis performed on this disc variant, in the figure 11 is presented the maximum temperature reached by the disc, which is $182.6^{\circ} \mathrm{C}$, see Fig. 11. In terms of heat flux, a maximum value of $1.182 \mathrm{e}+6 \mathrm{~W} / \mathrm{m}^{2}$ can be observed in Fig. 12. You can also see the distribution of heat flux on the first disk variant in Table 2. A decrease in temperature can be observed compared to the first variant. 


\subsubsection{Disc variant 3 of the disc - results obtained}

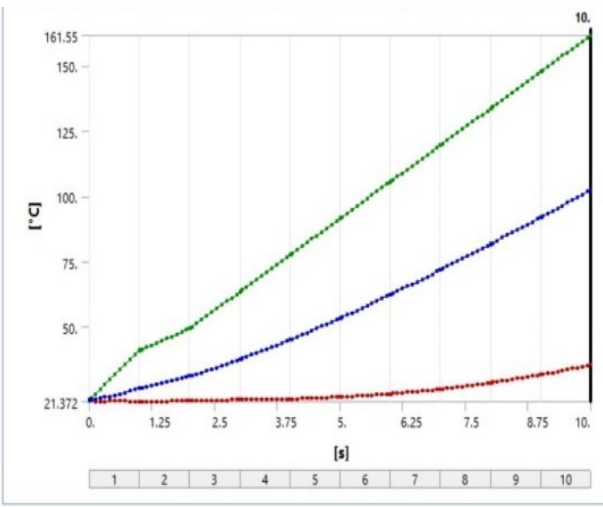

Fig. 13. Time-temperature graph: disc 3.

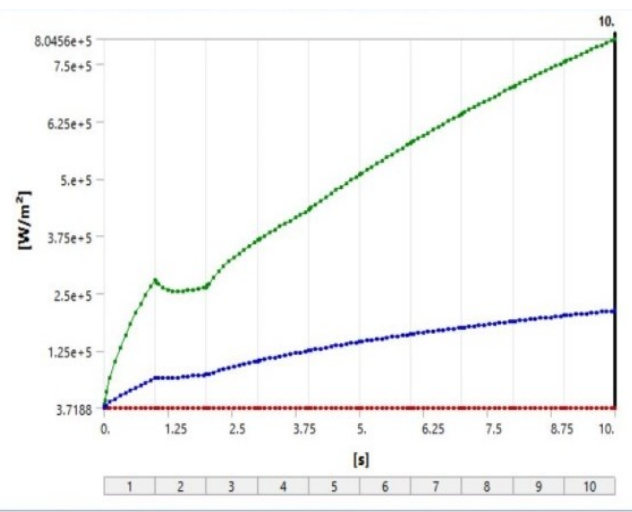

Fig. 14. Heat flow-time graph: disc 3.

In this third disc variant, a geometry was used that contains large diameter disc ventilation perforations, the material used being semi-metal, and the disc thickness is 10 $\mathrm{mm}$. As can be seen from the analysis performed on this disc variant, the maximum temperature reached by the disc in an interval of $10 \mathrm{~s}$ is $161.55^{\circ} \mathrm{C}$, as can be seen in Fig. 13. Regarding the heat flux, a maximum value of $8.0456 \mathrm{e}+5 \mathrm{~W} / \mathrm{m}^{2}$ can be observed in Fig. 14. You can also see the distribution of heat flux on the first disk variant in Table 2. A decrease in temperature can be observed compared to the first two variants.

\subsubsection{Variant 4 of the disc - results obtained}

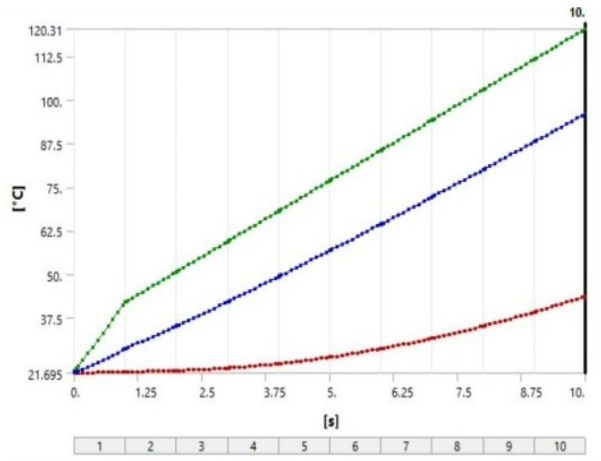

Fig. 15. Time-temperature graph: disc 4 .

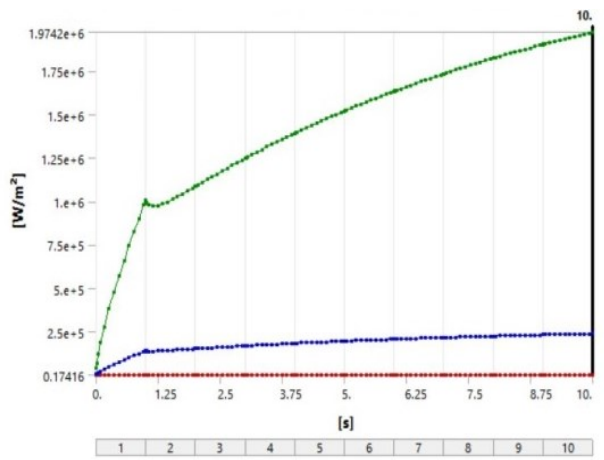

Fig. 16. Heat flow-time graph: disc 4 .

In this fourth disc variant, a more complex geometry was used that contains both medium diameter disc ventilation perforations and four slots on a depth of $5 \mathrm{~mm}$, the material used being semi-metal, and the disc thickness is $10 \mathrm{~mm}$. As can be seen from the analysis performed on this disc variant, the maximum temperature reached by the disc in an interval of $10 \mathrm{~s}$ is $120.31^{\circ} \mathrm{C}$, a rather large decrease in temperature can be observed in Fig. 15 , compared to the first three variants of disc. Regarding the heat flux, a maximum value of $1.9742 \mathrm{e}+5 \mathrm{~W} / \mathrm{m}^{2}$ can be observed in Fig. 16. You can also see the distribution of heat flux on the first disk variant in Table 2. 


\subsubsection{Disc variant 5 - results obtained}
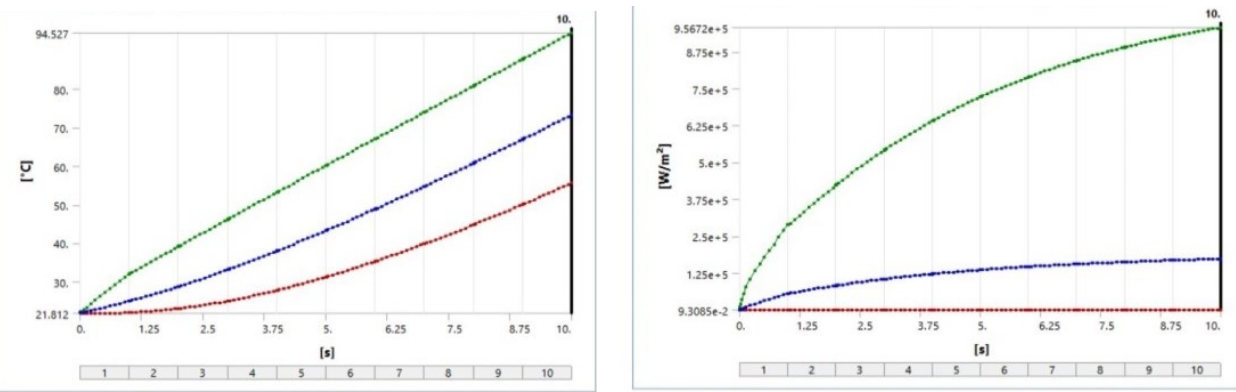

Fig. 17. Temperature-time graph: disc $5 . \quad$ Fig. 18. Thermal flow-time graph: disc 5.

For the fifth disc variant, a complex geometry was used that contains ventilation milling in certain directions in the studied disc, the material used being semi-metal, and the disc thickness is $10 \mathrm{~mm}$. As can be seen from the analysis performed on this disc variant, the maximum temperature reached by the disc in a range of $10 \mathrm{~s}$ is $94.52{ }^{\circ} \mathrm{C}$, as can be seen in Fig. 17. In terms of heat flux, a maximum value of $9.5672 \mathrm{e}+5 \mathrm{~W} / \mathrm{m}^{2}$ can be observed in Fig. 18. You can also see the distribution of heat flux on the first disk variant in Table 2. This discs variant obtained the best result in terms of temperature at which reaches the disc in 10 seconds.

\subsection{Disc material}

Following the thermal analysis, new sets of simulations were made, for alternative materials for brake discs [11]. In the Table 3 below are presented the results for both castiron and for ceramic materials used for disc variant five.

Table 3. Disc material.

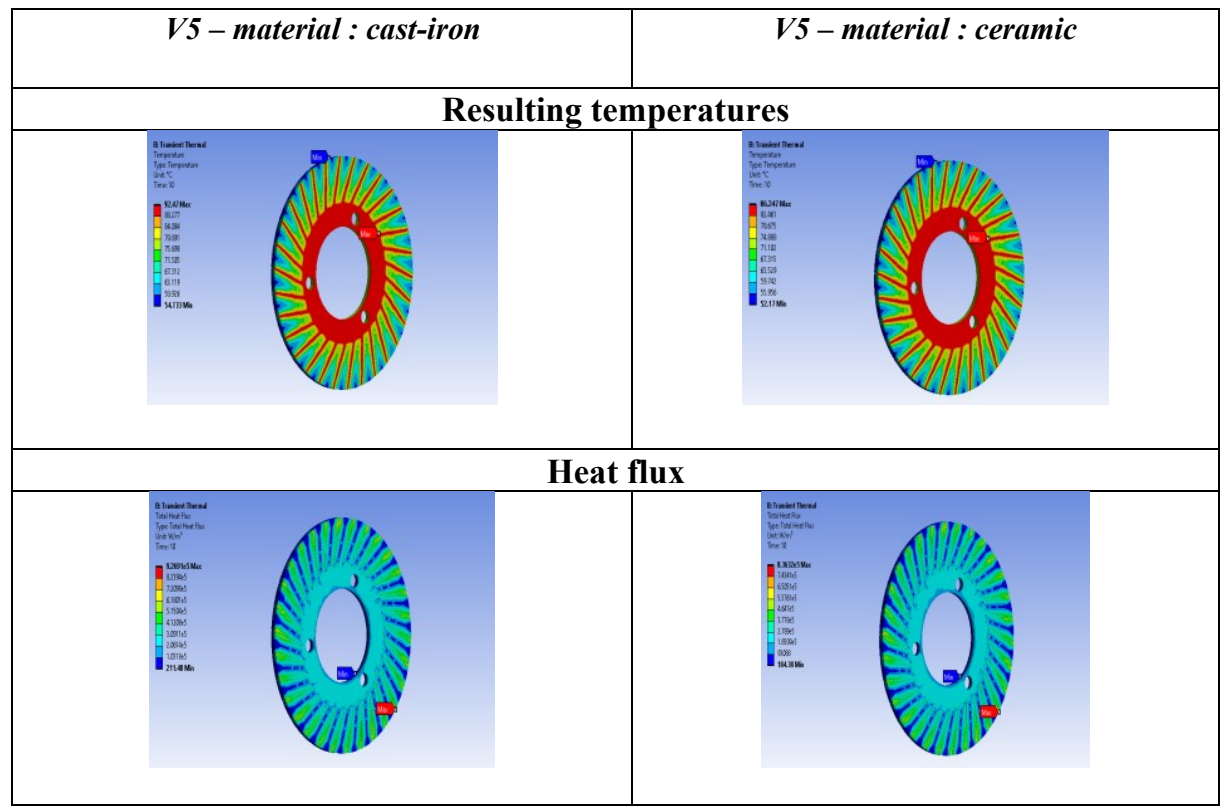




\subsubsection{Disc variant 5: cast-iron: results obtained}

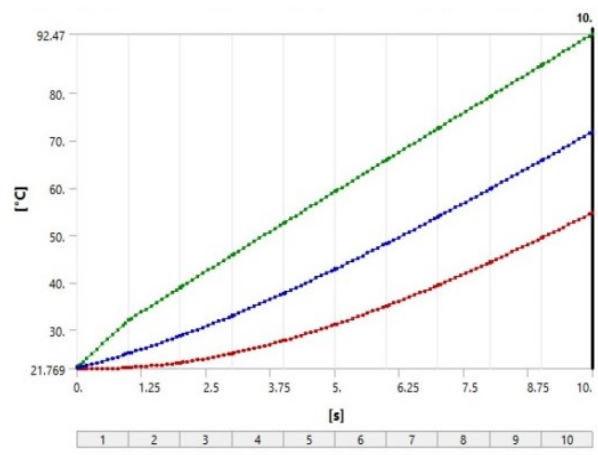

Fig. 19. Time-temperature graph: cast iron.

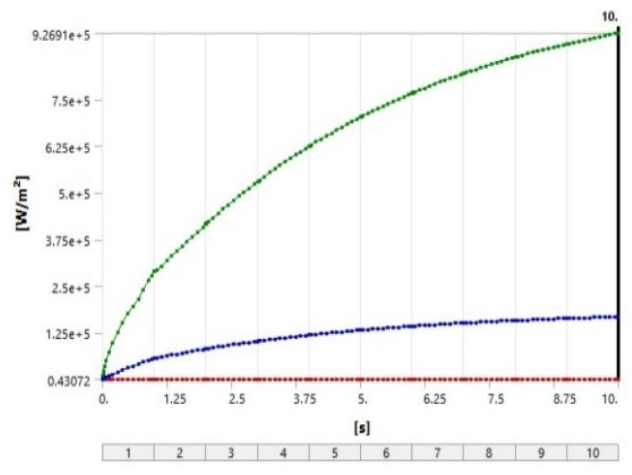

Fig. 20. Heat flow graph time: cast iron.

To perform this analysis, according to specialty literature [12-13], the disc with the best results in terms of heating temperature at the time of impact was used, namely variant 5 of the disc. This time the semi-metallic material was replaced with the cast iron material. From the obtained graph presented in Fig. 19 there is a slight decrease in temperature, but not a large enough one. The maximum temperature reached by the disc is $92.47^{\circ} \mathrm{C}$. Regarding the heat flux, a maximum value of $9.2691 \mathrm{e}+5 \mathrm{~W} / \mathrm{m}^{2}$ can be observed in Fig. 20 . You can also see the distribution of heat flux on the first disk variant in Table 3.

\subsubsection{Disc variant 5: Ceramic: results obtained}

The last material used to make a comparison between those used previous is the ceramic. It is known and usually used in automotive industry for its thermal properties [14-15].

As can be seen from Fig. 19 and Fig. 20, the values obtained from thermal analysis are much lower than for semi-metallic and cast-iron, which make it the most efficient.

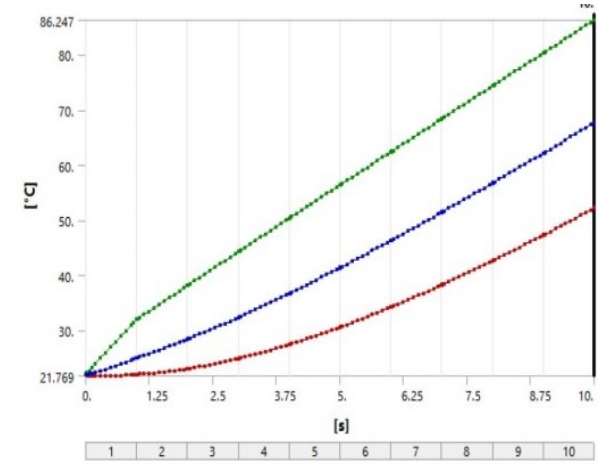

Fig. 21. Time-temperature graph: Ceramic.

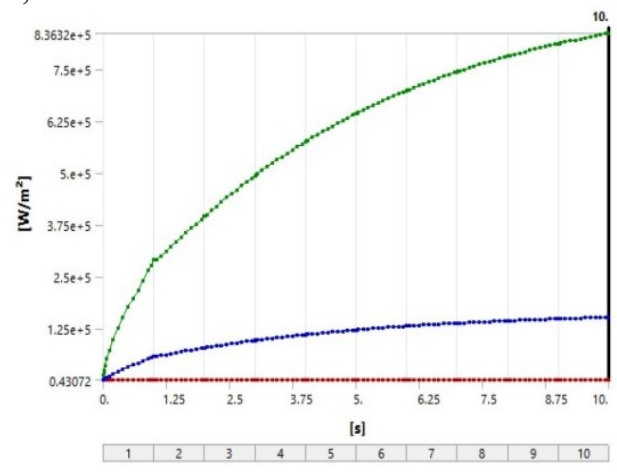

Fig. 22. Heat flow graph time: Ceramic.

At this analysis a maximum temperature of $86.24^{\circ} \mathrm{C}$ was obtained, this temperature being the lowest temperature obtained after all the analyzes performed. The heat flux obtained a value of $8.3632 \mathrm{e}+5 \mathrm{~W} / \mathrm{m}^{2}$, this value can be seen in Fig. 22 .

In the table 4 are presented the properties for each material used in the analysis, due to a high thermal conductivity, the ceramic material disc obtained lower temperature values after transient thermal analysis [16-18]. 
Table 4. Material properties.

\begin{tabular}{|c|c|c|c|}
\hline Material properties & $\begin{array}{c}\text { Disc } \\
\text { (Semi metallic) }\end{array}$ & $\begin{array}{c}\text { Disc } \\
\text { (Ceramic) }\end{array}$ & $\begin{array}{c}\text { Disc } \\
\text { (Cast iron) }\end{array}$ \\
\hline Thermal conductivity $\mathrm{W} \mathrm{m}^{-1} \mathrm{C}^{-1}$ & 60,5 & 32 & 52 \\
\hline Density $\mathrm{kg} \mathrm{m}^{-3}$ & 7850 & 3750 & 6999 \\
\hline Specific heat $\mathrm{JKg}^{-1} \mathrm{C}^{-1}$ & 434 & 786.6 & 499.6 \\
\hline Poissons ratio & 0,3 & 0,27 & 0,28 \\
\hline Coefficient of linear expansion $\mathrm{K}^{-1}$ & $0,1210^{-6}$ & $2,610^{-6}$ & $0,1110^{-6}$ \\
\hline Young Modulus GPa & 20 & 24 & 110 \\
\hline Bulk Modulus Pa & $1.66 \mathrm{e}+11$ & $1.57 \mathrm{e}+11$ & $6.21 \mathrm{e}+10$ \\
\hline
\end{tabular}

\section{Conclusions}

After the realization of the three constructive variants of the tricycle, it was concluded that the third variant is the most capable to record very good results in terms of its ability to skid in a controlled manner. After the complete replacement of the braking system, this being an essential element both for skidding and for better performances, because similar tricycle can reach up to $120 \mathrm{~km} / \mathrm{h}$ and other modifications have been made such as: front wheel, rear axle, adding a grooved mechanism and pedal position sensors. In this work, the aim was to improve the quality and the performances of use of this tricycle. Following the first set of thermal analyzes performed using the ANSYS software, it was concluded that variant five is the most efficient in terms of heating temperatures. In the second set of analyzes it was found that the ceramic material adds a much more significantly improvement than the other materials commonly used in the production of brake discs.

\section{References}

1. S. Siddharth, S. R. Rahul, Z. F. Mohd, S. F. Mohd, S. Mohd, S. Omprakash, Int. J. Sci. Res. Rev. 7, 187 (2019)

2. Metha, F. K. Christopher, A. B. Bentang, Int. J. Sustain. Transp. 3, 20 (2020)

3. G. E. Vikas, K. Ankur, M. E. Sameer, P. Kartik (2012)

4. F. Vishal, J. Gajanan, M. Ramachandran, ICMMRE 2017, Design, Modelling and Analysis of Tilted Human Powered Vehicle, (Sikkim, India, 2017)

5. A. Faizal, I. Indrawanto, A. B. Bentang, L. S. Poetro, P. S. Sigit, AASEC 2018, Frame modal analysis for an electric three-wheel vehicle, (Bandung, Indonesia, 2018)

6. V. Manthan, S. Balbir, J. Eng. Sci. Technol. Rev. 10 (2017)

7. K. M. Sharath, H. Junling, ASEE-NE 2017, Study on Transient Thermal Analysis of a Disc Brake During Braking and Releasing Periods, (Lowell, USA, 2017)

8. B. C. Chetan, S. M. Anurag, N. P. Nikhil, P. Baskar, J. Appl. Res. Technol. 16 (2018)

9. P. Gongyu, C. Rongyu, Adv. Mater. Sci. Eng. 2018 (2018)

10. C. Pinca-Bretotean, P. Cosmin, J. Ana, J. Phys. Conf. Ser. 1426 (2020)

11. Ș. Voloacă, G. Frățilă, Ann. Acad. Rom. Sci. Ser. Math. Appl. 111 (2011)

12. J. Rakesh, R. J. Anupam, Int. J. Mech. Eng. Technol. 4, 67 (2016)

13. A. Belhocine, I. A. Oday, Multiscale Sci. Eng. 2, 27 (2020)

14. A. Belhocine, A. Asif, Aust. J. Mech. Eng. 1 (2020)

15. R. B. Matthew, Advanced Ceramic Matrix Composites (2017)

16. A. Belhocine, W. Z. W. Omar, Rev. Cient. Rural, 116-128 (2017)

17. S. Nadica, A. I. Oday, S. Josef, G. Ivan, G. Jasna, SERBIATRIB '19, Study the structural problem in the brake system applying a different pressure function, (Kragujevac, Serbia, 2019)

18. A. Belhocine, A.R.A. Bakar, B. Mostefa, Aust. J. Mech. Eng. 14 (2016) 